\title{
Determinants of Life Insurance Policy Surrenders
}

\author{
Thomas Poufinas ${ }^{1 *}$, Gina Michaelide ${ }^{2}$ \\ ${ }^{1}$ Department of Economics, Democritus University of Thrace, Komotini, Greece \\ ${ }^{2}$ Graduate Program in Business Mathematics, Athens University of Economics and Business \& University of Athens, Athens, \\ Greece \\ Email: *tpoufinas@gmail.com
}

How to cite this paper: Poufinas, T. and Michaelide, G. (2018) Determinants of Life Insurance Policy Surrenders. Modern Economy, 9, 1400-1422.

https://doi.org/10.4236/me.2018.98089

Received: July 2, 2018

Accepted: August 7, 2018

Published: August 10, 2018

Copyright (C) 2018 by authors and Scientific Research Publishing Inc. This work is licensed under the Creative Commons Attribution International License (CC BY 4.0).

http://creativecommons.org/licenses/by/4.0/

\begin{abstract}
Life insurance policies assist individuals maintain the value of their money and build savings to be used in the future. However in times of crisis their attitude may change. On one hand, they have an interest in keeping their policies, as they can be used to cover their future, medium-term or long-term needs in case of retirement or death. On the other hand, they may need the premium money or the accumulated savings to meet short-term needs so they lapse or surrender them-when a surrender value exists. A natural question is what are the drivers of the behavior of the insured? When do they decide to stop them and when do they choose to maintain them? We use linear regression to identify how certain main macroeconomic variables (Gross Domestic Product (GDP) per capita growth, unemployment, inflation, short-term and long term interest rates, and consumer confidence index) can explain the behavior of the insured towards keeping or interrupting their life insurance policy. We do that for pension savings (pure and plain vanilla endowment-including pensions), term life, whole life and unit linked individual policies.
\end{abstract}

\section{Keywords}

Policyholder Behavior, Insurance Policy, Lapses, Surrenders, Macroeconomic Figures

\section{Introduction}

Life insurance policies offer capital preservation and growth, as well as protection, depending on the product type. It is to the interest of the policyholders-insured to maintain them so as to achieve their goal. It is to the interest of the insurers that the policies are active so that they meet their premium and 
profitability targets. However, there are circumstances, especially periods of extended crises, under which the policyholders may decide to terminate their policies. They have to take a decision that balances their short-term cash needs with their long-term, future capital needs.

There is a series of factors that affect such a decision. Unemployment for example, which has significantly increased globally and especially in the southern European countries, is a reason to interrupt premium payments, as the premium is a cash flow that may not be affordable for the unemployed. However, the unemployed may feel safer if they continue paying their premium so as to have a lump sum or an annuity when they retire or an amount for their keen in case they decease. We trust that unemployment and other country figures, which we exhibit and explain below, can be determinants of policyholder behavior.

We believe that our approach offers something over and above what has been done in the past. So far two hypotheses have been primarily in the spotlight [1]; the interest rate hypothesis, according to which lapses are primarily related to the interest rate fluctuations and the emergency fund hypothesis, according to which cash values (that result from a policy surrender) serve as an emergency fund to be drawn in distressed personal finance times. The former states that life insurance disintermediation activity is related to the differential return offered by alternative investment vehicles over returns on life savings products. Consequently, an increase in interest rates is expected to cause an increase in policy surrenders as policyholders move funds to market instruments that offer higher rates. According to the latter, lapses are expected to increase during recessions as policyholders may not be able to continue paying their premium. As a result higher surrender activity is expected in times of severe unemployment or declining personal income [1] [2].

We therefore investigate the relationship of policy lapses or surrenders with the macroeconomic figures of a country. The macroeconomic variables of interest are the GDP per capita growth, the unemployment, the inflation rate, the short-term and the long term interest rates, and the consumer confidence index. We attempt to find the significance of these variables on the termination (surrender or lapse) of a life insurance policy of a savings or protection type. More specifically the products of interest are characterized as 1) pension savings, incorporating pure and plain vanilla endowment-including pensions, 2) term life, 3) whole life and 4) unit linked individual policies.

Our dataset comes from an insurance company in Greece with regards to the policy lapses or surrenders. Data is taken from the World Bank (GDP per capita growth), the OECD (short and long term interest rates, Consumer Confidence Index) and Eurostat (inflation and unemployment), when it comes to the macroeconomic figures of Greece for the years 2005 to 2017.

We believe that that topic is of great significance to the insurers above all, as they need to understand how the evolution of certain macroeconomic variables affects the behavior of their policyholders. This is because it is widely recognized 
that for an insurance company it is preferable that it retains its clientele, rather than losing it and attempting to acquire a new one. In other words, it has been estimated by the insurance market that the acquisition cost is (much) higher than the retention cost. As a result, if an insurer knows how the insured are going to react when the economic environment changes, then it can adjust its retention policy so as to make it appealing for the policyholders to retain their policies.

As is highlighted in our paper, we find empirical evidence that that the policy retention (or rather termination from our perspective) depends on the level of consumer confidence and long-term interest rates for all products. When the consumer confidence drops the policy retention drops (or the policy termination increases). When the long interest rates increase, then the policy lapses or surrenders increase. In addition it depends on the unemployment rate for the protection products and from the CPI for the savings products. On one hand, when unemployment increases, then the insured tend to lapse their protection products. On the other hand, when the inflation increases, then the insured tend to surrender their savings products. This is key intelligence for the insurers, as it allows them to draft potential strategies in order to retain policies by looking at the different macroeconomic variables. For example, when they anticipate increased unemployment, then they can offer premium holiday; alternatively they can offer a waiver of premium rider in case of unemployment at the inception of the policy. They can offer inflation-linked investments underlying the insurance savings product, so that the insured feel protected in periods of increased inflation. In addition, they can consider higher profit sharing, so that when long-term interest rates increase, then a higher portion of the over-performance is returned to the insured; hence the latter have an incentive not to surrender. Finally, when the consumer confidence drops, especially in periods of extended crisis, they can offer premium holidays, or paid up possibilities, so that the insured can "freeze" their policies until they can pay the required premium again. We feel that this is the added value of our manuscript to the research in the field, as well as to the practitioners in the life insurance business.

Last but not least, we look for explanatory variables for a country of the European south, that has been hit the most by the recent economic-financial crisis, namely Greece. We trust that the evidence we find and the recommendations we make can be extended to other countries of southern Europe that lived a similar experience and this is an additional point that our paper highlights.

There are admittedly other directions, which are not part of our research and have been left for future investigation. These directions point out that the lapse rate is correlated to the characteristics of the insured, the characteristics of the product, the characteristics of the agent and to factors relevant to the external environment [1].

The paper is organized as follows; Section 2 introduces the necessary definitions and notation. Section 3 discusses the existing literature in the area of in- 
surance policy lapses and surrenders and compares it with our study. Section 4 presents the data, the variables and the methodology we used to identify the determinants of the life policy surrenders or lapses. Section 5 exhibits the results and identifies their implications per product category. Section 6 paves out potential future research that we have already identified. Finally, Section 7 concludes the paper.

\section{Definitions and Notation}

\subsection{Definitions}

Policy surrender occurs when the policyholder no longer wishes to continue his or her insurance plan and decides to terminate the policy before the maturity. When a policyholder surrenders the contract receives a build-up amount called cash value. In most of the cases surrender is a result of either financial reasons or because the needs of the policyholder are changed compared to the initial ones.

Lapse of a policy occurs when the policyholder is unable to pay the remaining premiums resulting to the termination of the coverage. If a policy lapses, then the policyholder is able to reinstate it within a period of time by paying the premium due. The lapse is different from the surrender as there is normally no cash value accumulated that the policyholder can collect upon the termination of the policy.

With the term withdrawal in the current study we refer to both lapses and surrenders in terms of APE (Annual Premium Equivalent). APE is defined as the premium that would have been paid in one full year independently of the premium payment frequency. Consequently, we are interested for each year for the percentage of withdrawals as a percent of the total APE. This is found by the ratio of APE lapsed or surrendered divided by the total APE.

A whole life insurance is a permanent coverage that provides the beneficiary with a payment of a sum assured following the loss of life of the insured party. Certain whole life policies require the payment of the premiums to be made within a predetermined period while others allow the payments to be made throughout the lifetime of the cover until the death of the insured. All policies are participating in the sense that they provide the policyholder an amount (dividend) when the investment return rate of the assets backing the liabilities overcomes the guaranteed interest rate.

An endowment insurance plan is a temporary coverage providing the insured amount to the policyholder upon his or her survival at the end of the coverage period or to the beneficiary upon the loss of life of the insured person. The endowment coverage is a combination of a life insurance and a savings plan. Most of the plans offer a profit participation feature. The premium can be either fixed until the maturity or for a predetermined period or even increasing. Certain endowment policies offer the policyholder the choice to receive the insured amount in the form of an annuity rather than as a lump sum.

A pure endowment insurance plan provides the policyholder with an insured 
amount at the maturity of the policy given that he or she is still alive. In contrast to the endowment insurance in most of the cases no beneficiary exists; however certain plans in case of death of the policyholder may return the accumulated premium to the beneficiaries without interest. One of the main reasons that the insured buy a pure endowment is the gradual saving of an amount for future use. Profit participation features are also present in this type of insurance policies.

Pensions are saving products, most of the times long term, aiming to provide the policyholder with an additional amount upon retirement. Pension plans included in this study are closed products (i.e. with no new business) with participation. In our paper we use the term pension savings to describe all the pension, pure endowment and endowment products, as these are the types of products that are primarily used to create retirement income.

The term life insurance covers the policyholder for the loss of his or her life, when the insured event occurs within a predetermined period as defined by the terms of the policy. Term life policies do not provide for a surrender value.

Unit linked insurance plans are primarily investment products that also provide certain benefits in case the insured person losses his or her life. All unit linked products invest the premium paid on mutual funds. The investment risk arising from this type of insurance product varies depending on the policyholder's risk profile. Premium payments can be either regular (periodic) or single (lump sum). Certain unit linked products offer a guaranteed minimum amount upon the occurrence of death or/and at the policy maturity date.

\subsection{Notation}

In our econometric models and regression tables (Appendix) we use the following notation;

$P B_{t}$ denotes the policyholder behavior as far as the policy termination (lapse or surrender) is concerned at time $t$.

$C P I_{t}$ denotes the consumer price index at time $t$.

$U_{t}$ denotes the unemployment (rate) at time $t$.

$S T R_{t}$ denotes the short-term interest rate at time $t$.

$L T R_{t}$ denotes the long-term interest rate at time $t$.

$C C I_{t}$ denotes the consumer confidence index at time $t$.

$G D P c_{t}$ denotes the GDP per capita growth at time $t$.

\section{Literature Review}

The literature on the determinants of the termination of life insurance policies can be split primarily in four categories. The first category examines the macroeconomic variables, the second looks at policy and policyholder characteristics, the third investigates company specific characteristics and the fourth looks at models that can price the surrender options. Our research falls under the first category. There is also some literature that tries to capture the effect of early 
policy termination to the company solvency and viability, but we consider it out of scope for the purposes of this paper.

Starting with the first category, Russel et al. [3] analyze life insurance policy surrender activity to discover that there is evidence that surrenders are related to the interest rates, the income per capita and the policy replacement activity. Their study addresses only cash value life insurance policies. Our study goes one step further in examining more and to some extend different macroeconomic figures. Moreover, we consider also policies that do not have a cash value (surrender value).

Kim [3] presents different surrender rate models to show that the logit model and complementary log-log model generally perform better than the (at the time existing) surrender rate models (such as the arctangent model). In addition, he finds that the proper surrender rate models may be different for the insurance policy types he considers: protection plans, education plans, endowment and annuities. The explanatory variables he considers are the difference between reference and crediting rates, the policy age since issuance, the financial crises, the unemployment, the economy growth rates and the seasonal effects. We use a partially different set of explanatory variables and a different set of models.

Kuo et al. [4] use the cointegration technique to find that the unemployment rate and the interest rate affect the lapse rate, with the latter being more economically significant in explaining the lapse rate dynamics. We examine a broader range of variables in our paper.

Outreville [1], quite early studies the hypothesis that policies lapse as the cash values are utilized by the policyholders as emergency funds, explaining that this hypothesis has not been extensively tested compared to the interest rate hypothesis that has received the most attention and empirical support by that time. He finds evidence that ordinary life insurance lapses within 13 months of issue are related to changes in expected personal income. This paper is complementary to ours, as we do not test for changes in the income of the policyholder.

Going to the second category, we realize that most of the papers examine macroeconomic variables and company specific characteristics at the same time. Hwang [5] investigates the main determinants of surrender dynamics in Taiwan life insurance companies for the period 1999-2009. He considers macroeconomic and company specific variables to realize that the age of the company, the business line and the home ownership ratio are the most significant variables. In addition the higher the reputation and the larger the company size, the lower the surrender rates. Our research focuses on a more recent period, on variables that are different to some extend and on a different country.

According to Haefeli and Ruprecht [6] the major insurance markets surrenders rates have not reached alarming levels. The U.S. experience for the period 2002-2010, which includes the most recent financial crisis, proves that the insurance industry was capable to cover the surrenders with its net operating cash-flow and (in aggregate) it has not been necessary to use the payouts of ma- 
ture bonds or sell liquid assets prematurely. They examine surrender behavior under normal and under extreme circumstances. They find (using specific examples) that collapsing confidence in a company could lead to mass surrenders and that (in the case of Korea) changes in the macroeconomic environment (interest rate and unemployment increase) lead to aggregate surrenders in the whole industry-depending on the product. The latter is in line with our findings; however we consider a wider range of macroeconomic variables.

Kiesenbauer [7] studies the determinants of lapse in the German life insurance industry. He considers macroeconomic indicators and company characteristics for five different product categories (endowment, annuity, term life, group and other, the latter being primarily unit linked business) to realize that the main lapse determinants are very similar across all product categories. The impact for the product category other is the opposite compared to the other product types. The economic variables are the buyer confidence, the current yield, the stock performance, the GDP and the unemployment (rate). These are similar to the macroeconomic variables we have considered. This makes Kiesenbauer's paper the closest to ours. In addition though he considers company specific variables; these are the company age, the distribution focus, the legal form, the company size and the participation rate spread.

As far as the third category is concerned, Gemmo and Götz [8] investigate which individual and household specific sociodemographic factors influence the surrender behavior of life insurance policyholders. They find that child birth and divorce (life events that cause a liquidity shock to the household) increase the likelihood of policy surrender. The same holds true for the acquisition of a dwelling and unemployment. This is different from our study, as it examined sociodemographic factors in contrast to macroeconomic variables, with unemployment though being a joint parameter.

Eling and Kiesenbauer [9] analyze the impact of product and policyholder characteristics on lapses in the German life insurance market for a time period that incorporates two periods of market turmoil, using generalized linear models. They realize that the product type and the policy age as well as the age and the gender of the policyholders are key drivers of lapses. These are policy-related or insured-related characteristics in contrast to our research that uses country-related macroeconomic variables.

The Canadian Institute of Actuaries [10] conducted a study on the lapse experience for 10-year term insurance. The research captured data on age, gender, amount, policy duration, smoking status, mortality rating, preferred underwriting classification, joint/single life, policy structure (standalone or rider), payment frequency, mode of payment (pre-authorized or other) and province. These are policy-related or insured-related characteristics in contrast to our research that uses country-related macroeconomic variables.

Fier and Liebenberg [11] test a microeconomic model of voluntary life insurance lapse behavior, linking the lapses with household related factors. They find 
evidence that lapses are related to large income shocks and to the purchase of a different life insurance policy. Moreover, they realize that age is an important decision factor; changes in income appear to more directly affect the decision to lapse for younger households compared to older households.

Milhaud et al. [12] show that certain policy features are important in explaining the decision of the policyholder to surrender a life insurance policy. Their results indicate that the duration of the policy and the profit benefit option prevail. In addition, older people tend to surrender more than others. The same applies to those who have periodic premium payments.

Purushotham [13] presents the results of a study of individual life insurance lapse experience in the United States. The study has been conducted jointly by LIMRA International and the Society of Actuaries, based on data provided by 22 individual life insurance companies for whole life, term life, universal life and variable life plans. The study also examines factors that are most likely to affect the lapse experience and these are gender, age at issuance, attained age, payment mode, risk class, smoking status and underwriting method. These are policy-related or insured-related characteristics in contrast to our research that uses country-related macroeconomic variables.

Going to the fourth category, De Giovanni [14] builds a rational expectation model that describes the policyholders' behavior in lapsing the policy. He considers a market model with stochastic interest rates to price the surrender option. Our research is not pricing the surrender option.

Although not immediately relevant to the determinants of life insurance policy termination, but relevant to the policyholder behavior, Valdez et al. [15] investigate the relationship between survivorship and persistency in life insurance. They use a follow up study to explore the mortality of those policies that terminated from a portfolio of life insurance policies of a major insurer. They model the time until a policy lapses and its subsequent mortality pattern, to find some evidence of mortality anti-selection. They also examined the resulting financial cost of the policy termination. Their research tackles a problem in a different direction from ours.

From the aforementioned discussion we realize a gap in the existing literature that we attempt to address; namely the examination of the impact of macroeconomic variables, such as the consumer confidence and the GDP per capita growth, as well as the inflation and the distinction of the interest rates in short-term interest rates and long-term interest rates. The unemployment rate as such has been researched in the past as well and the same holds true somehow with the interest rate, with no distinction however in short-term and long-term interest rate. In addition, not all different product types have been researched. In line with this identification of gap(s) in the existing literature, our contribution comprises primarily of the following elements: 1 ) We use a large dataset, i.e. the insurance portfolio of one the biggest life insurance companies of the country (in terms of premium) over a period of 13 years. 2) We employ a somewhat dif- 
ferent set of macroeconomic variables (although with some overlaps) and investigate their impact on policy termination per product type. 3) This is the first empirical study for the Greek life insurance market to the best of our knowledge. 4) The period from 2005 to 2017 contains the biggest contemporary financial crisis. The (combination of the) last two points post another important contribution; namely the identification of the behavior of the policyholders in a country that has been hit the most by the crisis. More countries in the European south have had similar experiences and can draw similar conclusions from our findings.

\section{Data, Variables and Methodology}

\subsection{Data}

Our insurance policy withdrawal (lapse and surrender) data come from an insurance company in Greece. They concern pension savings (pure and plain vanilla endowment-including pensions), term life, whole life and unit linked individual policies. They are taken on a monthly basis for the period January 2005 to December 2017.

The insurance company from which our dataset comes is and has always been one of the top five life insurers in the country. Moreover, it is one of the oldest insurance companies and has been selling the products under investigation for more than 30 years. It has always been among the pioneers in terms of product development and their distribution via different channels. Hence, there is no distribution channel bias. The life products available in the Greek market are similar to the ones we consider in our study. In addition, it has always been a point of reference by its peers. As a result, we trust that this specific insurance company is representative of the life insurance market and there is no sample selection bias. One could say that it is a good replica of the entire market. Consequently, the findings of our study can be extended to the insurance industry of Greece. As Greece is a country of the European south that has had a hard time in weathering the crisis, we feel that our evidence can be applied to other countries in the region that faced a similar experience.

The source of GDP per capita growth is the World Bank and the data are annual. We have used the monthly equivalent of the annual growth in order to estimate the monthly GDP per capita growth. The interest rate (long term and short term) and consumer confidence data come from OECD and their frequency is monthly. The inflation and unemployment percentages have been taken from Eurostat and they are monthly as well. For all the variables the period under examination is the same, with the exception of GDP per capita growth for which data is available until December 2016.

\subsection{Variables}

The dependent variable is the policy withdrawal (lapse and surrender) rate of the aforementioned insurance products, which is an indicator of the policyholder 
behavior. The independent variables are the inflation, the unemployment, the short-term and long-term interest rates, the consumer confidence index and the GDP per capita growth for Greece. The rationale for the choice of the independent variables lies in the belief that the economic environment of the country, as reflected by these macroeconomic figures, affects policyholder behavior.

The choice of withdrawal (lapse or surrender) rate as the dependent variable is explained by the fact that this is exactly what we want to measure as policyholder behavior; i.e. the tendency to terminate or keep a policy based on the evolution of certain macroeconomic variables. The intuition behind the selection of macroeconomic variables lies within the rationale that certain conditions affect the stance of the policyholders. Starting with inflation, we felt that its increase most likely would lead to an increase in the withdrawal ratio, possibly with a time lag, as the insured are forced to pay higher prices for goods and services and therefore terminate their policy and keep the premium money. We anticipated a similar effect for unemployment for similar reasons. In that direction, we also wanted to test the impact of GDP per capita growth; does it privilege or does it hinter lapses and surrenders? We used GDP per capita growth as view it as a good replica of an individual's income growth. We expected that reduced consumer confidence increases lapses and surrenders, as policyholders are consumers after all. Finally, we wanted to investigate the impact of interest rates. As life insurance products have a long-term horizon we distinguished between long-term and short-term interest rates so as to have a clear indication of which one affects lapses and surrenders. We felt that their increase made people believe that they can beat the performance of insurers and thus they have a tendency to lapse or surrender their policies.

\subsection{Methodology}

In order to identify the relation between the dependent and the independent variables we run linear regressions, with the ordinary least squares (OLS) method. Our regression equation is of the form:

$$
P B_{t}=b_{0}+b_{1} C P I_{t}+b_{2} U_{t}+b_{3} S T R_{t}+b_{4} L T R_{t}+b_{5} C C I_{t}+b_{6} G D P c_{t}+e_{t}
$$

or

$$
P B_{t}=b_{0}+b_{1} C P I_{t-1}+b_{2} U_{t-1}+b_{3} S T R_{t}+b_{4} L T R_{t}+b_{5} C C I_{t}+b_{6} G D P c_{t}+e_{t}
$$

or

$$
P B_{t}=b_{0}+b_{1} C P I_{t-2}+b_{2} U_{t-1}+b_{3} S T R_{t}+b_{4} L T R_{t}+b_{5} C C I_{t}+b_{6} G D P c_{t-1}+e_{t}
$$

or

$$
P B_{t}=b_{0}+b_{1} C P I_{t-1}+b_{2} U_{t}+b_{3} S T R_{t-1}+b_{4} L T R_{t}+b_{5} C C I_{t}+b_{6} G D P c_{t-1}+e_{t} .
$$

The rationale behind the choice of the regression variants is explained by the fact that the intention of a policyholder to lapse or surrender a policy may be expressed with a time lag versus the evolution of the macroeconomic figure under examination. As such, we trust that depending on the product, the decision 
to withdraw from or retain the policy is taken one or two years after the change in inflation, unemployment or GDP per capita. This means that a policyholder waits for one or two years after the increase of inflation or unemployment or the decrease of GDP per capita growth to make up his or her mind with regards to the policy retention.

We run the regressions with the Stata econometric software. The relevant regression tables are at the end of the paper. We tested for heteroskedastisity and we corrected it using the robust standard errors approach, wherever present.

\section{Results and Implications}

\subsection{Results}

Using the aforementioned econometric models we found the following results per product category.

\subsubsection{Whole Life}

We find that the withdrawal rate is positively correlated at all levels with the unemployment and negatively correlated with the GDP per capita growth at all levels, when we assume no time lag. The other variables post no statistical significance. There is positive correlation though with the inflation, the short-term interest rate and the long-term interest rate. There is negative correlation with the consumer confidence index.

We see that the withdrawal rate is positively correlated at all levels with the unemployment, at the $10 \%$ level with the long-term interest rates and negatively correlated at levels with the GDP per capita growth and the consumer confidence index, when we assume a one year time lag for the inflation and the unemployment rate. The rest of the variables exhibit no statistical significance; however, there is positive correlation with the inflation and the short-term interest rate.

We realize that the withdrawal rate is positively correlated with the unemployment and the long-term interest rates at all levels, when we consider a two year time lag for the inflation and a one year time lag for the unemployment and the GDP per capita growth. There is negative correlation at all levels with the consumer confidence index and at the $10 \%$ level with the short-term interest rate. The remaining of the variables has no statistical significance. We observe though that the GDP per capita growth is positively correlated and the inflation is negatively correlated.

We infer that the withdrawal rate is positively correlated at all levels with the unemployment and at the $5 \%$ level with the GDP per capita growth. It is negatively correlated at all levels with the consumer confidence index and at the 5\% level with the short-term interest rate, when we use a one year time lag for the inflation, the short-term interest rates and the GDP per capita growth. The other variables have no statistical significance; however, there is positive correlation with the long-term interest rate and negative correlation with the inflation. 


\subsubsection{Term Life}

We notice that the withdrawal rate is positively correlated with the long-term interest rates at the $5 \%$ level and negatively correlated with the consumer confidence index at the $5 \%$ level, with no time lag. The rest of the variables show no statistical significance; however there is positive correlation with the unemployment, the GDP per capita growth and negative correlation with the inflation and the short-term interest rates.

We observe that the withdrawal rate is positively correlated with and the inflation at the 5\% level, when we apply a one year time lag for the inflation and the unemployment rate. It is negatively correlated at the $5 \%$ level with the consumer confidence index. Although the remaining of the variables shows no statistical significance, there is positive correlation with the unemployment, the GDP per capita growth and the long-term interest rates, and negative correlation with the short-term interest rate.

We infer that the withdrawal rate is positively correlated with the inflation at all levels, with the long-term interest rates and with the unemployment at the 5\% significance level and negatively correlated with the consumer confidence index at the $5 \%$ level when we apply a two year time lag for the inflation and a one year time lag for the unemployment and the GDP per capita growth. The rest of the variables show no statistical significance; however, there is negative correlation with the short-term interest rate and the GDP per capita growth.

We realize that the withdrawal rate is positively correlated with the unemployment at all levels, the inflation and with the short-term rate at the $5 \%$ level when we use a one year time lag for the inflation, the short-term interest rates and the GDP per capita growth. The other variables exhibit no statistical significance; there is positive correlation though with the long-term interest rates and negative correlation with the consumer confidence index and with the GDP per capita growth.

\subsubsection{Pension Savings}

We discover that the withdrawal rate is positively correlated with the long-term interest rates at all significance levels and negatively correlated with the consumer confidence index at all levels, and the unemployment at the $5 \%$ level with no time lag. The rest of the variables show no statistical significance; however there is positive correlation with the GDP per capita growth and with the short-term interest rates and negative correlation with the inflation.

We find that the withdrawal rate is positively correlated with the inflation at all levels, with the long-term interest rates at the $5 \%$ significance level. It is negatively correlated with the consumer confidence index at levels, when we apply a one year time lag for the inflation and the unemployment rate. Although the remaining of the variables shows no statistical significance, there is positive correlation with the unemployment. Moreover, there is negative correlation with the short-term interest rate and the GDP per capita growth.

We see that the withdrawal rate is positively correlated with the long-term in- 
terest rates and inflation at all significance levels when we apply a two year time lag for the inflation and a one year time lag for the unemployment and the GDP per capita growth. It is negatively correlated with the consumer confidence index at all levels, with the unemployment at the $10 \%$ confidence level. In addition, there is positive correlation with the short-term interest rate and negative correlation with the GDP per capita growth but with no significance.

We realize that the withdrawal rate is positively correlated with the inflation and long-term interest rates at all levels, with the unemployment at the $5 \%$ significance level, with the short-term interest rate at the $10 \%$ level, when we use a one year time lag for the inflation, the short-term interest rates and the GDP per capita growth. The consumer confidence index is negatively correlated at the 5\% significance level. There is negative correlation with the GDP per capita growth but with no significance.

\subsubsection{Unit Linked}

We observe that the withdrawal rate is positively correlated with the long-term interest rate at all levels, with the GDP per capita growth at the 5\% significance level, with no time lag. The other variables show no statistical significance; however, there is positive correlation with inflation and negative correlation with unemployment, short-term interest rates and consumer confidence index.

We infer that the withdrawal rate is positively correlated with the inflation and long-term interest rates at all levels and with the GDP per capita growth at all levels, when we apply a one year time lag for the inflation and the unemployment rate. It is negatively correlated with the short term interest rates at the $5 \%$ level and with the consumer confidence index at the $10 \%$ level. The unemployment rate is positively correlated, but not statistically significant.

We notice that the withdrawal rate is positively correlated with the inflation and the long term interest rates at all levels and negatively correlated at the 5\% level with the consumer confidence index, when we apply a two year time lag for the inflation and a one year time lag for the unemployment and the GDP per capita growth. The remaining variables exhibit no statistical significance; however there is positive correlation with the unemployment and the short-term interest rates and negative correlation with the GDP per capita growth.

We note that the withdrawal rate is positively correlated with the inflation, the unemployment and the long-term interest rates at all significance levels, when we use a one year time lag for the inflation, the short-term interest rates and the GDP per capita growth. The rest of the variables show no statistical significance. There is though positive correlation with the short-term interest rate and the consumer confidence index and negative correlation with the GDP per capita growth.

\subsection{Heteroskedastisity}

We tested for heteroskedasticity with White's test. We corrected it wherever present with robust standard errors. We summarize our findings below. 


\section{Whole life}

We detected heteroskedasticity only in model 2 . We corrected it with robust standard errors with no change in any of the significance levels.

\section{Term life}

We detected heteroskedasticity only in models 1 and 2. We corrected it with robust standard errors with no change in any of the significance levels.

\section{Pension savings}

We detected heteroskedasticity only in model 1 . We corrected it with robust standard errors with no change in any of the significance levels.

\section{Unit linked}

We detected heteroskedasticity only in models 1 and 3 . We corrected it with robust standard errors with no change in any of the significance levels.

\subsection{Descriptive Statistics}

In order to have a more complete presentation of our data, we show the basic descriptive statistics per product type and per model/equation (Tables 1-16).

If we attempt to interpret the above findings we see that term life exhibits the highest mean lapse rate, with unit linked following; pension savings are third, whereas whole life shows the lowest mean lapse rate. The median shows the same pattern. When it comes to standards deviation, whole life has the smallest, unit linked the second smallest and term life comes third, whereas pension

Table 1. Whole life descriptive statistics as per regression Equation (1).

\begin{tabular}{cccccccc}
\hline & $\mathrm{PB}_{\mathrm{t}}$ & $\mathrm{CPI}_{\mathrm{t}}$ & $\mathrm{U}_{\mathrm{t}}$ & $\mathrm{STR}_{\mathrm{t}}$ & $\mathrm{CCI}_{\mathrm{t}}$ & $\mathrm{LTR}_{\mathrm{t}}$ & $\mathrm{GDPc}_{\mathrm{t}}$ \\
\hline Mean & 0.0762 & 0.0174 & 0.1688 & 0.0153 & 0.9841 & 0.0872 & -0.0014 \\
Median & 0.0681 & 0.0210 & 0.1530 & 0.0094 & 0.9839 & 0.0730 & -0.0011 \\
Std. Dev. & 0.0410 & 0.0220 & 0.0778 & 0.0163 & 0.0173 & 0.0564 & 0.0082 \\
Kurtosis & 0.6588 & -1.0659 & -1.7353 & -0.5703 & -1.4134 & 2.7571 & -0.8266 \\
Skewness & 0.9034 & -0.1683 & 0.1546 & 0.8445 & 0.0806 & 1.7072 & 0.0084 \\
Min & 0.0262 & -0.0290 & 0.0680 & -0.0032 & 0.9544 & 0.0330 & -0.0154 \\
Max & 0.2206 & 0.0570 & 0.2900 & 0.0511 & 1.0133 & 0.2924 & 0.0126 \\
\hline
\end{tabular}

Table 2. Whole life descriptive statistics as per regression Equation (2).

\begin{tabular}{cccccccc}
\hline & $\mathrm{PB}_{\mathrm{t}}$ & $\mathrm{CPI}_{\mathrm{t}-1}$ & $\mathrm{U}_{\mathrm{t}-1}$ & $\mathrm{STR}_{\mathrm{t}}$ & $\mathrm{CCI}_{\mathrm{t}}$ & $\mathrm{LTR}_{\mathrm{t}}$ & $\mathrm{GDPc}_{\mathrm{t}}$ \\
\hline Mean & 0.0762 & 0.0199 & 0.1580 & 0.0153 & 0.9841 & 0.0872 & -0.0014 \\
Median & 0.0681 & 0.0280 & 0.1175 & 0.0094 & 0.9839 & 0.0730 & -0.0011 \\
Std. Dev. & 0.0410 & 0.0216 & 0.0767 & 0.0163 & 0.0173 & 0.0564 & 0.0082 \\
Kurtosis & 0.6588 & -0.8009 & -1.5187 & -0.5703 & -1.4134 & 2.7571 & -0.8266 \\
Skewness & 0.9034 & -0.4652 & 0.4847 & 0.8445 & 0.0806 & 1.7072 & 0.0084 \\
Min & 0.0262 & -0.0290 & 0.0680 & -0.0032 & 0.9544 & 0.0330 & -0.0154 \\
Max & 0.2206 & 0.0570 & 0.2900 & 0.0511 & 1.0133 & 0.2924 & 0.0126 \\
\hline
\end{tabular}


Table 3. Whole life descriptive statistics as per regression Equation (3).

\begin{tabular}{cccccccc}
\hline & $\mathrm{PB}_{\mathrm{t}}$ & $\mathrm{CPI}_{\mathrm{t}-2}$ & $\mathrm{U}_{\mathrm{t}-1}$ & $\mathrm{STR}_{\mathrm{t}}$ & $\mathrm{CCI}_{\mathrm{t}}$ & $\mathrm{LTR}_{\mathrm{t}}$ & $\mathrm{GDPc}_{\mathrm{t}-1}$ \\
\hline Mean & 0.0809 & 0.0210 & 0.1640 & 0.0138 & 0.9834 & 0.0851 & -0.0002 \\
Median & 0.0754 & 0.0290 & 0.1240 & 0.0076 & 0.9832 & 0.0680 & -0.0008 \\
Std. Dev. & 0.0464 & 0.0211 & 0.0766 & 0.0164 & 0.0170 & 0.0547 & 0.0089 \\
Kurtosis & 4.2090 & -0.6524 & -1.6690 & -0.4246 & -1.3555 & 3.2696 & -0.9389 \\
Skewness & 1.4728 & -0.5896 & 0.2969 & 0.9123 & 0.1667 & 1.8270 & 0.0289 \\
Min & 0.0262 & -0.0290 & 0.0680 & -0.0033 & 0.9544 & 0.0330 & -0.0154 \\
Max & 0.3204 & 0.0570 & 0.2900 & 0.0511 & 1.0133 & 0.2924 & 0.0145 \\
\hline
\end{tabular}

Table 4. Whole life descriptive statistics as per regression Equation (4).

\begin{tabular}{cccccccc}
\hline & $\mathrm{PB}_{\mathrm{t}}$ & $\mathrm{CPI}_{\mathrm{t}-1}$ & $\mathrm{U}_{\mathrm{t}}$ & $\mathrm{STR}_{\mathrm{t}-1}$ & $\mathrm{CCI}_{\mathrm{t}}$ & $\mathrm{LTR}_{\mathrm{t}}$ & $\mathrm{GDPc}_{\mathrm{t}-1}$ \\
\hline Mean & 0.0809 & 0.0184 & 0.1724 & 0.0157 & 0.9834 & 0.0851 & -0.0002 \\
Median & 0.0754 & 0.0260 & 0.1715 & 0.0107 & 0.9832 & 0.0680 & -0.0008 \\
Std. Dev. & 0.0464 & 0.0214 & 0.0758 & 0.0157 & 0.0170 & 0.0547 & 0.0089 \\
Kurtosis & 4.2090 & -0.9583 & -1.7080 & -0.5116 & -1.3555 & 3.2696 & -0.9389 \\
Skewness & 1.4728 & -0.2902 & 0.0335 & 0.7833 & 0.1667 & 1.8270 & 0.0289 \\
Min & 0.0262 & -0.0290 & 0.0680 & -0.0032 & 0.9544 & 0.0330 & -0.0154 \\
Max & 0.3204 & 0.0570 & 0.2900 & 0.0511 & 1.0133 & 0.2924 & 0.0145 \\
\hline
\end{tabular}

Table 5. Term life descriptive statistics as per regression Equation (1).

\begin{tabular}{cccccccc}
\hline & $\mathrm{PB}_{\mathrm{t}}$ & $\mathrm{CPI}_{\mathrm{t}}$ & $\mathrm{U}_{\mathrm{t}}$ & $\mathrm{STR}_{\mathrm{t}}$ & $\mathrm{CCI}_{\mathrm{t}}$ & $\mathrm{LTR}_{\mathrm{t}}$ & $\mathrm{GDPc}_{\mathrm{t}}$ \\
\hline Mean & 0.1765 & 0.0174 & 0.1688 & 0.0153 & 0.9841 & 0.0872 & -0.0014 \\
Median & 0.1726 & 0.0210 & 0.1530 & 0.0094 & 0.9839 & 0.0730 & -0.0011 \\
Std. Dev. & 0.0540 & 0.0220 & 0.0778 & 0.0163 & 0.0173 & 0.0564 & 0.0082 \\
Kurtosis & 1.9344 & -1.0659 & -1.7353 & -0.5703 & -1.4134 & 2.7571 & -0.8266 \\
Skewness & 1.0141 & -0.1683 & 0.1546 & 0.8445 & 0.0806 & 1.7072 & 0.0084 \\
Min & 0.0893 & -0.0290 & 0.0680 & -0.0032 & 0.9544 & 0.0330 & -0.0154 \\
Max & 0.4141 & 0.0570 & 0.2900 & 0.0511 & 1.0133 & 0.2924 & 0.0126 \\
\hline
\end{tabular}

Table 6. Term life descriptive statistics as per regression Equation (2).

\begin{tabular}{cccccccc}
\hline & $\mathrm{PB}_{\mathrm{t}}$ & $\mathrm{CPI}_{\mathrm{t}-1}$ & $\mathrm{U}_{\mathrm{t}-1}$ & $\mathrm{STR}_{\mathrm{t}}$ & $\mathrm{CCI}_{\mathrm{t}}$ & $\mathrm{LTR}_{\mathrm{t}}$ & $\mathrm{GDPc}_{\mathrm{t}}$ \\
\hline Mean & 0.1765 & 0.0199 & 0.1580 & 0.0153 & 0.9841 & 0.0872 & -0.0014 \\
Median & 0.1726 & 0.0280 & 0.1175 & 0.0094 & 0.9839 & 0.0730 & -0.0011 \\
Std. Dev. & 0.0540 & 0.0216 & 0.0767 & 0.0163 & 0.0173 & 0.0564 & 0.0082 \\
Kurtosis & 1.9344 & -0.8009 & -1.5187 & -0.5703 & -1.4134 & 2.7571 & -0.8266 \\
Skewness & 1.0141 & -0.4652 & 0.4847 & 0.8445 & 0.0806 & 1.7072 & 0.0084 \\
Min & 0.0893 & -0.0290 & 0.0680 & -0.0032 & 0.9544 & 0.0330 & -0.0154 \\
Max & 0.4141 & 0.0570 & 0.2900 & 0.0511 & 1.0133 & 0.2924 & 0.0126 \\
\hline
\end{tabular}


Table 7. Term life descriptive statistics as per regression Equation (3).

\begin{tabular}{cccccccc}
\hline & $\mathrm{PB}_{\mathrm{t}}$ & $\mathrm{CPI}_{\mathrm{t}-2}$ & $\mathrm{U}_{\mathrm{t}-1}$ & $\mathrm{STR}_{\mathrm{t}}$ & $\mathrm{CCI}_{\mathrm{t}}$ & $\mathrm{LTR}_{\mathrm{t}}$ & $\mathrm{GDPc}_{\mathrm{t}-1}$ \\
\hline Mean & 0.1732 & 0.0210 & 0.1640 & 0.0138 & 0.9834 & 0.0851 & -0.0002 \\
Median & 0.1672 & 0.0290 & 0.1240 & 0.0076 & 0.9832 & 0.0680 & -0.0008 \\
Std. Dev. & 0.0536 & 0.0211 & 0.0766 & 0.0164 & 0.0170 & 0.0547 & 0.0089 \\
Kurtosis & 2.0476 & -0.6524 & -1.6690 & -0.4246 & -1.3555 & 3.2696 & -0.9389 \\
Skewness & 1.0636 & -0.5896 & 0.2969 & 0.9123 & 0.1667 & 1.8270 & 0.0289 \\
Min & 0.0823 & -0.0290 & 0.0680 & -0.0033 & 0.9544 & 0.0330 & -0.0154 \\
Max & 0.4141 & 0.0570 & 0.2900 & 0.0511 & 1.0133 & 0.2924 & 0.0145 \\
\hline
\end{tabular}

Table 8. Term life descriptive statistics as per regression Equation (4).

\begin{tabular}{cccccccc}
\hline & $\mathrm{PB}_{\mathrm{t}}$ & $\mathrm{CPI}_{\mathrm{t}-1}$ & $\mathrm{U}_{\mathrm{t}}$ & $\mathrm{STR}_{\mathrm{t}-1}$ & $\mathrm{CCI}_{\mathrm{t}}$ & $\mathrm{LTR}_{\mathrm{t}}$ & $\mathrm{GDPc}_{\mathrm{t}-1}$ \\
\hline Mean & 0.1732 & 0.0184 & 0.1724 & 0.0157 & 0.9834 & 0.0851 & -0.0002 \\
Median & 0.1672 & 0.0260 & 0.1715 & 0.0107 & 0.9832 & 0.0680 & -0.0008 \\
Std. Dev. & 0.0536 & 0.0214 & 0.0758 & 0.0157 & 0.0170 & 0.0547 & 0.0089 \\
Kurtosis & 2.0476 & -0.9583 & -1.7080 & -0.5116 & -1.3555 & 3.2696 & -0.9389 \\
Skewness & 1.0636 & -0.2902 & 0.0335 & 0.7833 & 0.1667 & 1.8270 & 0.0289 \\
Min & 0.0823 & -0.0290 & 0.0680 & -0.0032 & 0.9544 & 0.0330 & -0.0154 \\
Max & 0.4141 & 0.0570 & 0.2900 & 0.0511 & 1.0133 & 0.2924 & 0.0145 \\
\hline
\end{tabular}

Table 9. Pension savings descriptive statistics as per regression Equation (1).

\begin{tabular}{cccccccc}
\hline & $\mathrm{PB}_{\mathrm{t}}$ & $\mathrm{CPI}_{\mathrm{t}}$ & $\mathrm{U}_{\mathrm{t}}$ & $\mathrm{STR}_{\mathrm{t}}$ & $\mathrm{CCI}_{\mathrm{t}}$ & $\mathrm{LTR}_{\mathrm{t}}$ & $\mathrm{GDPc}_{\mathrm{t}}$ \\
\hline Mean & 0.1158 & 0.0174 & 0.1688 & 0.0153 & 0.9841 & 0.0872 & -0.0014 \\
Median & 0.0980 & 0.0210 & 0.1530 & 0.0094 & 0.9839 & 0.0730 & -0.0011 \\
Std. Dev. & 0.0589 & 0.0220 & 0.0778 & 0.0163 & 0.0173 & 0.0564 & 0.0082 \\
Kurtosis & 0.5321 & -1.0659 & -1.7353 & -0.5703 & -1.4134 & 2.7571 & -0.8266 \\
Skewness & 0.9454 & -0.1683 & 0.1546 & 0.8445 & 0.0806 & 1.7072 & 0.0084 \\
Min & 0.0248 & -0.0290 & 0.0680 & -0.0032 & 0.9544 & 0.0330 & -0.0154 \\
Max & 0.3149 & 0.0570 & 0.2900 & 0.0511 & 1.0133 & 0.2924 & 0.0126 \\
\hline
\end{tabular}

Table 10. Pension savings descriptive statistics as per regression Equation (2).

\begin{tabular}{cccccccc}
\hline & $\mathrm{PB}_{\mathrm{t}}$ & $\mathrm{CPI}_{\mathrm{t}-1}$ & $\mathrm{U}_{\mathrm{t}-1}$ & $\mathrm{STR}_{\mathrm{t}}$ & $\mathrm{CCI}_{\mathrm{t}}$ & $\mathrm{LTR}_{\mathrm{t}}$ & $\mathrm{GDPc}_{\mathrm{t}}$ \\
\hline Mean & 0.1158 & 0.0199 & 0.1580 & 0.0153 & 0.9841 & 0.0872 & -0.0014 \\
Median & 0.0980 & 0.0280 & 0.1175 & 0.0094 & 0.9839 & 0.0730 & -0.0011 \\
Std. Dev. & 0.0589 & 0.0216 & 0.0767 & 0.0163 & 0.0173 & 0.0564 & 0.0082 \\
Kurtosis & 0.5321 & -0.8009 & -1.5187 & -0.5703 & -1.4134 & 2.7571 & -0.8266 \\
Skewness & 0.9454 & -0.4652 & 0.4847 & 0.8445 & 0.0806 & 1.7072 & 0.0084 \\
Min & 0.0248 & -0.0290 & 0.0680 & -0.0032 & 0.9544 & 0.0330 & -0.0154 \\
Max & 0.3149 & 0.0570 & 0.2900 & 0.0511 & 1.0133 & 0.2924 & 0.0126 \\
\hline
\end{tabular}


Table 11. Pension savings descriptive statistics as per regression Equation (3).

\begin{tabular}{cccccccc}
\hline & $\mathrm{PB}_{\mathrm{t}}$ & $\mathrm{CPI}_{\mathrm{t}-2}$ & $\mathrm{U}_{\mathrm{t}-1}$ & $\mathrm{STR}_{\mathrm{t}}$ & $\mathrm{CCI}_{\mathrm{t}}$ & $\mathrm{LTR}_{\mathrm{t}}$ & $\mathrm{GDPc}_{\mathrm{t}-1}$ \\
\hline Mean & 0.1104 & 0.0210 & 0.1640 & 0.0138 & 0.9834 & 0.0851 & -0.0002 \\
Median & 0.0922 & 0.0290 & 0.1240 & 0.0076 & 0.9832 & 0.0680 & -0.0008 \\
Std. Dev. & 0.0597 & 0.0211 & 0.0766 & 0.0164 & 0.0170 & 0.0547 & 0.0089 \\
Kurtosis & 0.5648 & -0.6524 & -1.6690 & -0.4246 & -1.3555 & 3.2696 & -0.9389 \\
Skewness & 0.9719 & -0.5896 & 0.2969 & 0.9123 & 0.1667 & 1.8270 & 0.0289 \\
Min & 0.0248 & -0.0290 & 0.0680 & -0.0033 & 0.9544 & 0.0330 & -0.0154 \\
Max & 0.3149 & 0.0570 & 0.2900 & 0.0511 & 1.0133 & 0.2924 & 0.0145 \\
\hline
\end{tabular}

Table 12. Pension savings descriptive statistics as per regression Equation (4).

\begin{tabular}{cccccccc}
\hline & $\mathrm{PB}_{\mathrm{t}}$ & $\mathrm{CPI}_{\mathrm{t}-1}$ & $\mathrm{U}_{\mathrm{t}}$ & $\mathrm{STR}_{\mathrm{t}-1}$ & $\mathrm{CCI}_{\mathrm{t}}$ & $\mathrm{LTR}_{\mathrm{t}}$ & $\mathrm{GDPc}_{\mathrm{t}-1}$ \\
\hline Mean & 0.1104 & 0.0184 & 0.1724 & 0.0157 & 0.9834 & 0.0851 & -0.0002 \\
Median & 0.0922 & 0.0260 & 0.1715 & 0.0107 & 0.9832 & 0.0680 & -0.0008 \\
Std. Dev. & 0.0597 & 0.0214 & 0.0758 & 0.0157 & 0.0170 & 0.0547 & 0.0089 \\
Kurtosis & 0.5648 & -0.9583 & -1.7080 & -0.5116 & -1.3555 & 3.2696 & -0.9389 \\
Skewness & 0.9719 & -0.2902 & 0.0335 & 0.7833 & 0.1667 & 1.8270 & 0.0289 \\
Min & 0.0248 & -0.0290 & 0.0680 & -0.0032 & 0.9544 & 0.0330 & -0.0154 \\
Max & 0.3149 & 0.0570 & 0.2900 & 0.0511 & 1.0133 & 0.2924 & 0.0145 \\
\hline
\end{tabular}

Table 13. Unit Linked descriptive statistics as per regression Equation (1).

\begin{tabular}{cccccccc}
\hline & $\mathrm{PB}_{\mathrm{t}}$ & $\mathrm{CPI}_{\mathrm{t}}$ & $\mathrm{U}_{\mathrm{t}}$ & $\mathrm{STR}_{\mathrm{t}}$ & $\mathrm{CCI}_{\mathrm{t}}$ & $\mathrm{LTR}_{\mathrm{t}}$ & $\mathrm{GDPc}_{\mathrm{t}}$ \\
\hline Mean & 0.1466 & 0.0174 & 0.1688 & 0.0153 & 0.9841 & 0.0872 & -0.0014 \\
Median & 0.1374 & 0.0210 & 0.1530 & 0.0094 & 0.9839 & 0.0730 & -0.0011 \\
Std. Dev. & 0.0471 & 0.0220 & 0.0778 & 0.0163 & 0.0173 & 0.0564 & 0.0082 \\
Kurtosis & 0.6381 & -1.0659 & -1.7353 & -0.5703 & -1.4134 & 2.7571 & -0.8266 \\
Skewness & 0.7955 & -0.1683 & 0.1546 & 0.8445 & 0.0806 & 1.7072 & 0.0084 \\
Min & 0.0304 & -0.0290 & 0.0680 & -0.0032 & 0.9544 & 0.0330 & -0.0154 \\
Max & 0.2979 & 0.0570 & 0.2900 & 0.0511 & 1.0133 & 0.2924 & 0.0126 \\
\hline
\end{tabular}

Table 14. Unit Linked descriptive statistics as per regression Equation (2).

\begin{tabular}{cccccccc}
\hline & $\mathrm{PB}_{\mathrm{t}}$ & $\mathrm{CPI}_{\mathrm{t}}$ & $\mathrm{U}_{\mathrm{t}}$ & $\mathrm{STR}_{\mathrm{t}}$ & $\mathrm{CCI}_{\mathrm{t}}$ & $\mathrm{LTR}_{\mathrm{t}}$ & $\mathrm{GDPc}_{\mathrm{t}}$ \\
\hline Mean & 0.1466 & 0.0174 & 0.1688 & 0.0153 & 0.9841 & 0.0872 & -0.0014 \\
Median & 0.1374 & 0.0210 & 0.1530 & 0.0094 & 0.9839 & 0.0730 & -0.0011 \\
Std. Dev. & 0.0471 & 0.0220 & 0.0778 & 0.0163 & 0.0173 & 0.0564 & 0.0082 \\
Kurtosis & 0.6381 & -1.0659 & -1.7353 & -0.5703 & -1.4134 & 2.7571 & -0.8266 \\
Skewness & 0.7955 & -0.1683 & 0.1546 & 0.8445 & 0.0806 & 1.7072 & 0.0084 \\
Min & 0.0304 & -0.0290 & 0.0680 & -0.0032 & 0.9544 & 0.0330 & -0.0154 \\
Max & 0.2979 & 0.0570 & 0.2900 & 0.0511 & 1.0133 & 0.2924 & 0.0126 \\
\hline
\end{tabular}


Table 15. Unit Linked descriptive statistics as per regression Equation (3).

\begin{tabular}{cccccccc}
\hline & $\mathrm{PB}_{\mathrm{t}}$ & $\mathrm{CPI}_{\mathrm{t}-2}$ & $\mathrm{U}_{\mathrm{t}-1}$ & $\mathrm{STR}_{\mathrm{t}}$ & $\mathrm{CCI}_{\mathrm{t}}$ & $\mathrm{LTR}_{\mathrm{t}}$ & $\mathrm{GDPc}_{\mathrm{t}-1}$ \\
\hline Mean & 0.1417 & 0.0210 & 0.1640 & 0.0138 & 0.9834 & 0.0851 & -0.0002 \\
Median & 0.1338 & 0.0290 & 0.1240 & 0.0076 & 0.9832 & 0.0680 & -0.0008 \\
Std. Dev. & 0.0486 & 0.0211 & 0.0766 & 0.0164 & 0.0170 & 0.0547 & 0.0089 \\
Kurtosis & 0.5484 & -0.6524 & -1.6690 & -0.4246 & -1.3555 & 3.2696 & -0.9389 \\
Skewness & 0.7412 & -0.5896 & 0.2969 & 0.9123 & 0.1667 & 1.8270 & 0.0289 \\
Min & 0.0304 & -0.0290 & 0.0680 & -0.0033 & 0.9544 & 0.0330 & -0.0154 \\
Max & 0.2979 & 0.0570 & 0.2900 & 0.0511 & 1.0133 & 0.2924 & 0.0145 \\
\hline
\end{tabular}

Table 16. Unit Linked descriptive statistics as per regression Equation (4).

\begin{tabular}{cccccccc}
\hline & $\mathrm{PB}_{\mathrm{t}}$ & $\mathrm{CPI}_{\mathrm{t}-1}$ & $\mathrm{U}_{\mathrm{t}}$ & $\mathrm{STR}_{\mathrm{t}-1}$ & $\mathrm{CCI}_{\mathrm{t}}$ & $\mathrm{LTR}_{\mathrm{t}}$ & $\mathrm{GDPc}_{\mathrm{t}-1}$ \\
\hline Mean & 0.1417 & 0.0184 & 0.1724 & 0.0157 & 0.9834 & 0.0851 & -0.0002 \\
Median & 0.1338 & 0.0260 & 0.1715 & 0.0107 & 0.9832 & 0.0680 & -0.0008 \\
Std. Dev. & 0.0486 & 0.0214 & 0.0758 & 0.0157 & 0.0170 & 0.0547 & 0.0089 \\
Kurtosis & 0.5484 & -0.9583 & -1.7080 & -0.5116 & -1.3555 & 3.2696 & -0.9389 \\
Skewness & 0.7412 & -0.2902 & 0.0335 & 0.7833 & 0.1667 & 1.8270 & 0.0289 \\
Min & 0.0304 & -0.0290 & 0.0680 & -0.0032 & 0.9544 & 0.0330 & -0.0154 \\
Max & 0.2979 & 0.0570 & 0.2900 & 0.0511 & 1.0133 & 0.2924 & 0.0145 \\
\hline
\end{tabular}

savings show the highest standard deviation. Apparently the insured have realized some sort of arbitrage opportunities in the whole life insurance policies, as their beneficiaries will always receive the sum assured.

\subsection{Implications}

\section{Whole life}

We observe that unemployment is positively correlated and significant at all levels for whole life products with all models. This means that as unemployment increases then lapses increase. Most likely this is the result of the fact that people keep their premium to pay current needs, feeling that accumulating a capital for future beneficiary needs in case of their death can wait. The consumer confidence index is negatively correlated with increasing significance as we move from model (1) to model (4). Hence, time lag is important; as the conditions deteriorate people may be willing to wait for one year, but after that they tend to lapse more intensely. This means that as the consumer confidence decreases then lapses increase. Decreased consumer confidence makes people feel that they should keep the premium money instead of using it to cover for future beneficiary needs. The long-term interest rate is always positively correlated with varying significance. This is most likely due to the fact that as long-term interest rates increase, the policyholders lapse, so as to use the premium money in investments that offer higher returns. Apparently they trust they can create the 
equivalent life insurance funds on their own. The remaining variables show mixed correlations and significance levels.

Term life

Term life exhibits the same exact behavior with whole life insurance, with different significance levels for some of the variables. This is expected as term life and whole life insurance are covering the same need with a different maturity/ time horizon.

\section{Pension savings}

The pension savings product termination is positively correlated with the CPI for all models ((2), (3) and (4)) for which it is significant. This yields that as CPI increases, the surrenders tend to increase. Most likely the insured tend to keep the premium money, as well as the surrender value, fearing they will need them to cove other expenses or needs. It is negatively correlated with the consumer confidence index at least at the $5 \%$ confidence level for all models, with a similar interpretation as for term and whole products. In addition, for pension savings, the policyholders benefit from the surrender value. The pension savings termination is positively correlated with the long-term interest rates at least at the 5\% confidence level for all models, with a similar interpretation as for term and whole products. Again, they also collect the surrender value, feeling that they can find alternative investment options which can give them higher return rates. The remaining variables show mixed correlations and significance levels.

\section{Unit linked}

Unit linked product terminations show the same pattern with the pension savings products, as is probably anticipated for CPI and long-term interest rates. The consumer confidence is also negatively correlated for the models it is statistically significant ((2) and (3)), at a smaller level though. These findings are probably anticipated, as pension savings and unit linked products cover the same need with a different investment risk level (profile).

Consequently, all product terminations are affected by the level of consumer confidence and interest rates, whereas the protection products are impacted also by the unemployment rate and the savings products by the CPI.

Therefore, if an insurer wanted to increase the retention of such policies it could offer index-linked products, with higher profit participation to safeguard against CPI and long-term interest rate increase. In addition, the insurance company could think of premium holidays and waiver of premium in case of unemployment riders, so as to retain policies in periods of decreased consumer confidence and increased unemployment.

\section{Further Research}

We have left for future research the development of models considering more macroeconomic variables or additional combinations of time lags. We also intend to further study the policyholder behavior linked with policyholder related variables; these are the demographic ones, such as the age and the gender, but 
also the insurance related ones, such as the policyholder value. The latter describes the total value of the policyholder for the insurer as measured by the number of policies that he or she maintains with the insurer or the total premium he or she pays. This reflects the entire cooperation of the policyholder with the insurance company. Our ongoing research aims also at finding whether in times of distressed economic environments the behavior of the insured changes towards keeping or lapsing their insurance policies.

\section{Conclusion}

In this paper we studied the policyholder behavior with regards to policy termination (lapse or surrender) in relation to certain macroeconomic variables (GDP per capita growth, unemployment, inflation, short-term and long term interest rates, and consumer confidence index) for four different types of products, whole life, term life, pension savings and unit linked. We realized, using the portfolio of a specific insurance undertaking that there is evidence that the policy termination is dependent from the level of consumer confidence and long-term interest rates for all products. In addition it depends on the unemployment rate for the protection products and from the CPI for the savings products. This allows insurers to draft potential strategies in order to retain policies by looking at the different macroeconomic variables.

\section{Conflicts of Interest}

The authors declare no conflicts of interest regarding the publication of this paper.

\section{References}

[1] Outreville, J.F. (1990) Whole-Life Insurance Lapse Rates and the Emergency Fund Hypothesis. Insurance: Mathematics and Economics, 9, 249-255. https://doi.org/10.1016/0167-6687(90)90002-U

[2] Russell, D.T., Fier, S.G., Carson, J.M. and Dumm, R.E. (2013) An Empirical Analysis of Life Insurance Policy Surrender Activity. Journal of Insurance Issues, 36, 35-57.

[3] Kim, G. (2005) Modeling Surrender and Lapse Rates with Economic Variables. North American Actuarial Journal, 9, 56-70. https://doi.org/10.1080/10920277.2005.10596225

[4] Kuo, W., Tsai, C. and Chen, W.-K. (2003) An Empirical Study on the Lapse Rate: The Cointegration Approach. The Journal of Risk and Insurance, 70, 489-508. https://doi.org/10.1111/1539-6975.t01-1-00061

[5] Hwanf, Y. (2016) Empirical Analysis of Surrender Dynamics in Taiwan Life Insurance Companies. Bulletin Français d'Actuariat, 16, 115-127.

[6] Haefeli, D. and Ruprecht, W. (Eds.) (2012) Surrenders in the Life Insurance Industry and Their Impact on Liquidity, Risk and Insurance Economics. The Geneva Association, Geneva/Basel.

[7] Kiesenbauer, D. (2012), Main Determinants of Lapse in the German Life Insurance Industry. North American Actuarial Journal, 16, 52-73. 
https://doi.org/10.1080/10920277.2012.10590632

[8] Gemmo, I. and Götz, M. (2016) Life Insurance and Demographic Change: An Empirical Analysis of Surrender Decisions Based on Panel Data. ICIR Working Paper Series, No. 24/16, 1-32.

[9] Eling, M. and Kiesenbauer, D. (2014) What Policy Features Determine Life Insurance Lapse? An Analysis of the German Market. The Journal of Risk and Insurance, 81, 241-269. https://doi.org/10.1111/j.1539-6975.2012.01504.x

[10] Canadian Institute of Actuaries (2014) Lapse Experience Study for 10-Year Term Insurance. Individual Life Experience Subcommittee, Canadian Institute of Actuaries, Ottawa.

[11] Fier, S.G. and Liebenberg, A.P. (2013) Life Insurance Lapse Behavior. North American Actuarial Journal, 17, 153-167. https://doi.org/10.1080/10920277.2013.803438

[12] Milhaud, X., Loisel, S. and Maume-Deschamps, V. (2011) Surrender Triggers in Life Insurance: What Main Features Affect the Surrender Behavior in a Classical Economic Context? Bulletin Français d'Actuariat, 11, 5-48.

[13] Purushotham, M. (2005) U.S. Individual Life Persistency Update, LIMRA International and the Society of Actuaries, U.S.A., Canada, United Kingdom, Australia, China.

[14] De Giovanni, D. (2010) Lapse Rate Modeling: A Rational Expectation Approach. Scandinavian Actuarial Journal, 1, 56-67. https://doi.org/10.1080/03461230802550649

[15] Valdez, E.A., Vadiveloo, J. and Dias, U. (2014) Life Insurance Policy Termination and Survivorship. Insurance: Mathematics and Economics, 58, 138-149.

[16] Eurostat (2017). http://ec.europa.eu/eurostat/statistics-explained/index.php/Inflation_in_the_euro_a rea

[17] Eurostat (2017). http://ec.europa.eu/eurostat/statistics-explained/index.php/Unemployment_statistic $\underline{s}$

[18] OECD (2017). https://data.oecd.org/leadind/consumer-confidence-index-cci.htm

[19] OECD (2017). https://data.oecd.org/interest/long-term-interest-rates.htm

[20] OECD (2017). https://data.oecd.org/interest/short-term-interest-rates.htm

[21] World Bank Data (2017). https://data.worldbank.org/indicator/NY.GDP.PCAP.CD 


\section{Appendix}

Table A1. Regressions with regression Equation (1).

\begin{tabular}{ccccc}
\hline & Whole Life & Term Life & Pension Savings & Unit Linked \\
\hline $\begin{array}{c}\text { Dependent Variable } \\
\text { PB }\end{array}$ & & & & \\
Independent Variables & & & & \\
CPI & 0.10856 & -0.13888 & -0.32679 & 0.34523 \\
& $(0.51153)$ & $(-0.37379)$ & $(-0.87868)$ & $(1.15515)$ \\
U & $0.333^{* * *}$ & 0.0322 & $-0.32948^{* *}$ & -0.01434 \\
& $(4.00191)$ & $(0.22104)$ & $(-2.25946)$ & $(-0.12233)$ \\
STR & 0.53531 & -0.32079 & 0.50215 & -0.62478 \\
& $(1.55595)$ & $(-0.53259)$ & $(0.83287)$ & $(-1.28955)$ \\
CCI & -0.37322 & $-1.02218^{* *}$ & $-1.64252^{* * *}$ & -0.382 \\
& $(-1.552)$ & $(-2.42794)$ & $(-3.89755)$ & $(-1.12801)$ \\
LTR & 0.04035 & $0.27541^{* *}$ & $0.54878^{* * *}$ & $0.55802^{* * *}$ \\
& $(0.57118)$ & $(2.22665)$ & $(4.43247)$ & $(5.60869)$ \\
GDPc & $-1.66813^{* * *}$ & 0.71856 & 0.02441 & $1.5974^{* *}$ \\
& $(-3.20942)$ & $(0.78966)$ & $(0.0268)$ & $(2.18237)$ \\
Constant & 0.37142 & $1.16132^{* * *}$ & $1.73803^{* * *}$ & 0.48207 \\
& $(1.51784)$ & $(2.71077)$ & $(4.05294)$ & $(1.39891)$ \\
Observations & 144 & 144 & 144 & 144 \\
\hline & 0.63488 & 0.35678 & 0.45797 & 0.45164 \\
\hline
\end{tabular}

Table A2. Regressions with regression Equation (2).

\begin{tabular}{|c|c|c|c|c|}
\hline & Whole Life & Term Life & Pension Savings & Unit Linked \\
\hline \multicolumn{5}{|l|}{ Dependent Variable } \\
\hline \multicolumn{5}{|l|}{ PB } \\
\hline \multicolumn{5}{|l|}{ Independent Variables } \\
\hline \multirow[t]{2}{*}{ CPI } & 0.17575 & $0.80337^{\star \star}$ & $1.50535^{\star \star \star}$ & $1.06874^{* * *}$ \\
\hline & $(0.89496)$ & $(2.40078)$ & $(5.0897)$ & $(4.30678)$ \\
\hline \multirow[t]{2}{*}{$\mathrm{U}$} & $0.27032^{\star * *}$ & 0.16832 & 0.0238 & 0.04327 \\
\hline & $(4.16921)$ & $(1.52347)$ & $(0.2437)$ & $(0.52813)$ \\
\hline \multirow[t]{2}{*}{ STR } & 0.36473 & -0.71565 & -0.05127 & $-1.02463^{\star *}$ \\
\hline & $(1.11198)$ & $(-1.28041)$ & $(-0.10379)$ & $(-2.47208)$ \\
\hline \multirow[t]{2}{*}{$\mathrm{CCI}$} & $-0.55939^{* *}$ & $-0.96774^{\star *}$ & $-1.34677^{* * *}$ & $-0.4815^{\star}$ \\
\hline & $(-2.57001)$ & $(-2.60914)$ & $(-4.10823)$ & $(-1.75059)$ \\
\hline \multirow[t]{2}{*}{ LTR } & $0.12046^{\star}$ & 0.17718 & $0.23688^{\star *}$ & $0.39128^{* * *}$ \\
\hline & $(1.6571)$ & $(1.43033)$ & $(2.16364)$ & $(4.25949)$ \\
\hline \multirow[t]{2}{*}{ GDPc } & $-1.61185^{\star * *}$ & 0.53803 & -0.47507 & $1.39888^{\star *}$ \\
\hline & $(-3.01663)$ & $(0.59092)$ & $(-0.59033)$ & $(2.07179)$ \\
\hline \multirow[t]{2}{*}{ Constant } & $0.56224^{\star \star}$ & $1.08254^{\star * \star}$ & $1.38695^{\star \star *}$ & $0.57586^{\star \star}$ \\
\hline & $(2.61111)$ & $(2.95035)$ & $(4.27673)$ & $(2.11638)$ \\
\hline Observations & 144 & 144 & 144 & 144 \\
\hline Adjusted R Squared & 0.62855 & 0.38008 & 0.59271 & 0.55081 \\
\hline
\end{tabular}


Table A3. Regressions with regression Equation (3).

\begin{tabular}{ccccc}
\hline & Whole Life & Term Life & Pension Savings & Unit Linked \\
\hline Dependent Variable & & & & \\
PB & & & & \\
Independent Variables & & & & \\
CPI & -0.25517 & $1.05255^{* * *}$ & $1.34893^{* * *}$ & $1.17289^{* * *}$ \\
& $(-1.46447)$ & $(4.62951)$ & $(6.92796)$ & $(6.94661)$ \\
U & $0.17304^{* * *}$ & $0.15811^{* *}$ & $-0.11734^{*}$ & 0.01682 \\
& $(2.86961)$ & $(2.00941)$ & $(-1.74129)$ & $(0.2879)$ \\
STR & $-0.49738^{*}$ & -0.21023 & 0.12402 & 0.05046 \\
& $(-1.7855)$ & $(-0.57836)$ & $(0.3984)$ & $(0.18693)$ \\
CCI & $-0.76078^{* *}$ & $-0.95996^{* *}$ & $-1.49596^{* * *}$ & $-0.63402^{* *}$ \\
& $(-2.50384)$ & $(-2.42127)$ & $(-4.40588)$ & $(-2.15337)$ \\
LTR & $0.18833^{* *}$ & $0.19184^{* *}$ & $0.32844^{* * *}$ & $0.34098^{* * *}$ \\
& $(2.56926)$ & $(2.00569)$ & $(4.00968)$ & $(4.80045)$ \\
GDPc & 0.61844 & -0.22871 & -0.14421 & -0.65146 \\
& $(1.25759)$ & $(-0.35642)$ & $(-0.26242)$ & $(-1.36708)$ \\
Constant & $0.79701^{* * *}$ & $1.05569^{* * *}$ & $1.5427^{* * *}$ & $0.70796^{* *}$ \\
& $(2.66361)$ & $(2.70386)$ & $(4.61372)$ & $(2.44162)$ \\
Observations & 156 & 156 & 156 & 156 \\
Adjusted R Squared & 0.52354 & 0.39273 & 0.64109 & 0.59354 \\
\hline
\end{tabular}

Table A4. Regressions with regression Equation (4).

\begin{tabular}{ccccc}
\hline & Whole Life & Term Life & Pension Savings & Unit Linked \\
\hline $\begin{array}{c}\text { Dependent Variable } \\
\text { PB }\end{array}$ & & & & \\
Independent Variables & & & & \\
CPI & -0.02868 & $0.70764^{* *}$ & $1.61016^{* * *}$ & $1.36171^{* * *}$ \\
& $(-0.13049)$ & $(2.45728)$ & $(6.28207)$ & $(6.13688)$ \\
U & $0.22751^{* * *}$ & $0.38942^{* * *}$ & $0.19408^{* *}$ & $0.24806^{* * *}$ \\
& $(2.93372)$ & $(3.83295)$ & $(2.14626)$ & $(3.1688)$ \\
STR & $-0.6806^{* *}$ & $0.92726^{* *}$ & $0.71328^{*}$ & 0.16407 \\
& $(-2.11699)$ & $(2.2015)$ & $(1.90268)$ & $(0.50554)$ \\
CCI & $-0.94169^{* * *}$ & -0.42134 & $-0.7626^{* *}$ & 0.00372 \\
& $(-3.24175)$ & $(-1.10711)$ & $(-2.25137)$ & $(0.01268)$ \\
LTR & 0.05566 & 0.16337 & $0.31956^{* * *}$ & $0.30634^{* * *}$ \\
& $(0.6911)$ & $(1.54839)$ & $(3.40298)$ & $(3.76823)$ \\
GDPc & $1.05165^{*}$ & -0.81293 & -0.71582 & -0.79996 \\
& $(1.94384)$ & $(-1.14692)$ & $(-1.13468)$ & $(-1.46477)$ \\
Constant & $0.97442^{* * *}$ & 0.4788 & $0.75879^{* *}$ & 0.04152 \\
& $(3.33902)$ & $(1.25232)$ & $(2.22987)$ & $(0.14094)$ \\
Observations & 156 & 156 & 156 & 156 \\
\hline & 0.51652 & 0.37880 & 0.60346 & 0.55243 \\
\hline
\end{tabular}

Source: Authors' calculations using the insurer's database (2017), Eurostat (2017a, 2017b), OECD (2017a, 2017b, 2017c) and the World Bank (2017) [16]-[21]. Notes: t-values in parenthesis; ${ }^{* * *}$ statistically significant at the $1 \%$ level; ${ }^{* *}$ statistically significant at the $5 \%$ level; *statistically significant at the $10 \%$ level. 